\title{
The Hybrid RFNN Control for a PMSM Drive Electric Scooter Using Rotor Flux Estimator
}

\author{
Chih-Hong $\operatorname{Lin}^{1}$ and Chih-Peng $\operatorname{Lin}^{2}$ \\ ${ }^{1}$ Department of Electrical Engineering, National United University, Miaoli 360, Taiwan \\ ${ }^{2}$ Department of Engineering, Su-Mo Enterprise Co. LTD, Taichung 430, Taiwan \\ Correspondence should be addressed to Chih-Hong Lin, jhlin@nuu.edu.tw
}

Received 29 June 2011; Revised 15 November 2011; Accepted 20 December 2011

Academic Editor: Uzay Kaymak

Copyright ( $\odot 2012$ C.-H. Lin and C.-P. Lin. This is an open access article distributed under the Creative Commons Attribution License, which permits unrestricted use, distribution, and reproduction in any medium, provided the original work is properly cited.

\begin{abstract}
The hybrid recurrent fuzzy neural network (HRFNN) control for permanent magnet synchronous motor (PMSM) drive system using rotor flux estimator is developed to control electric scooter in this paper. First, the dynamic models of a PMSM drive system were derived in according to electric scooter. Owing to the load of electric scooter exited many uncertainties, for example, nonlinear friction force of the transmission belt, and so forth. The electric scooter with nonlinear uncertainties made the PI controller to disable speed tracking control. Moreover, in order to reduce interference of encoder and cost down, an HRFNN control system using rotor flux estimator was developed to control PMSM drive system in order to drive electric scooter. The rotor flux estimator consists of the estimation algorithm of rotor flux position and speed based on the back electromagnetic force (EMF) in order to supply with HRFNN controller. The HRFNN controller consists of the supervisor control, RFNN, and compensated control with adaptive law is applied to PMSM drive system. The parameters of RFNN are trained according to different speeds in electric scooter. The electric scooter is operated to provide disturbance torque. To show the effectiveness of the proposed controller, comparative studies with PI controller are demonstrated by experimental results.
\end{abstract}

\section{Introduction}

In recent years, for the purpose of reducing air pollution and enhancing environmental protection, quite a few countries require their automotive industries to develop electric vehicles in place of gasoline-powered automobiles gradually. Here we put our attention on the development and research of electric scooters since scooters are much more widespread than automobiles for individual transportation in Asia. The AC servo drives, including PMSMs (both trapezoidal and sinusoidal types), switched reluctance motors, and induction motors, have been widely used in robotics, computernumerically-controlled (CNC) machine tools, elevators, and many other applications in the area of mechatronics $[1,2]$ for decades.

To achieve fast four-quadrant operation and smooth starting and acceleration, the field-oriented control [1-3], or vector control, is used in the design of AC servo drives.
Compared with induction servo motors, a PM synchronous motor has such advantages as higher efficiency owing to the absence of rotor losses and lower no-load current below the rated speed; moreover, its decouple control performance is much less sensitive to the parameter variations of the motor $[1,2]$.

Recently much research has been done on the applications of fuzzy neural network (FNN) systems, which have the advantages of both fuzzy systems and neural networks, in the control fields to deal with nonlinearities and uncertainties of the control systems [4-15]. Moreover, the FNNs are universal approximators $[6,7]$, which can approximate any dynamics to a prespecified accuracy by the learning process [6]. The fuzzy neural approximator presented in Leu et al. [8] tuned on line to approximate the unknown nonlinear dynamic systems for adaptive control. The supervisory FNN controller proposed in Lin et al. [9] comprised a supervisory controller, which is designed to stabilize the system states 
around a defined bound region, and an FNN sliding-mode controller, which combines the advantages of the slidingmode control with robust characteristics and the FNN with online learning ability. Kung [10] proposed an adaptive fuzzy controller to cope with the friction and external load effect of a permanent magnet linear synchronous motor (SM) drive. Kim and Lee [11] presented a fuzzy disturbance observer to achieve good trajectory tracking for permanent magnet linear SM drives in the presence of external disturbance and internal parameter uncertainties. The key method of the proposed intelligent control is that system uncertainty is approximated by a fuzzy system and the fuzzy system is used to counteract the effect of the lumped disturbance in the design of control systems. Though the favorable control performance was achieved, some constrained conditions and prior system information were required in the intelligent control system. Fuzzy neural network (FNN) is multilayered connectionist network, which brings the learning abilities of neural networks to realize the elements and functions of fuzzy systems. The FNN possesses the merits of lowlevel learning and computation power of neural networks, and the high-level human-like thinking and reasoning of fuzzy theory. In $[12,13]$, an adaptive FNN control scheme is proposed for the position tracking control of permanent magnet linear SM drives. The robust control performance is achieved when uncertainties occur including a nonlinear friction force. The FNN is a feedforward network structure, which performs well on algebraic mapping of input-output training data. However, the FNN is being used to model dynamic structures. It is not more suitable to describe the system with dynamic behavior. On the other hand, a recurrent FNN (RFNN) has superior dynamic capability than the FNN $[14,15]$. Since the RFNN has an internal feedback loop to capture system dynamics, the dynamic response of a system can be captured without using external feedback through delays. The RFNN is a dynamic mapping and usually obtains good control performance in the presence of system uncertainties. Lin et al. [16] proposed an RFNN controller for the trajectory tracking of a permanent magnet linear SM drives with structure and parameter learning phases concurrently. Wang and Lee [17] designed a self-adaptive RFNN control scheme for controlling an autonomous underwater vehicle. The RFNN was trained to model the inverse dynamics of the vehicle and then utilized as a feedforward controller to compute the nominal torque of the vehicle along a desired trajectory. Lin et al. [18] addressed the application of a recurrent functional link-based FNN control to the periodic reference trajectory tracking issue for permanent magnet linear SM servo drives. Although these RFNN techniques can incorporate fuzzy rules with dynamic elements for better approximation of nonlinear dynamics, how to build a suitable-sized network structure and develop online training algorithms for the RFNN is the major challenging problem. Moreover, the tuning of controllers should also be considered for achieving more robust control. Su and Liaw [19] combined a mixed feedforward/feedback controller and a disturbance observer for the adaptive position tracking control of permanent magnet linear SM drives. In [20], a robust feedforward/feedback control scheme was proposed to address the sensitivity of control performance of permanent magnet linear SM drives to external disturbances. Though the favorable tracking performance was guaranteed, the proposed control approach needs to know the system dynamics. One approach in dealing with major changes and uncertainty in nonlinear dynamical processes is through neural modeling and control. Nho and Meckl [21] incorporated a neural-network identifier and a simple PD controller to control an articulated robot. The neural-network identifier was trained to represent the inverse dynamics of the robot and then was used in the computed torque control architecture. Lee and Teng [22] proposed a novel RFNN control structure for identifying and controlling nonlinear dynamic systems. In the control scheme, an unknown system was identified by the RFNN identifier to provide the sensitivity information about the system to a RFNN controller, while the RFNN controller generated a control signal to minimize the error between actual system output and desired output. Although these approach are very effective, one of the important problems is how to design a powerful network with a simple structure and less time in training. Therefore, this paper presents hybrid recurrent fuzzy neural network (HRFNN); control PMSM drive system using rotor flux estimator is developed to control electric scooter in this paper. The method is not dependent upon the predetermined characteristics of the motor and can adapt to any change in the motor characteristics. Owing to PI controller cannot process with nonlinear uncertainties such as electric scooter. Therefore, a HRFNN control system using rotor flux estimator was developed to control PMSM drive system in order to drive electric scooter. The rotor flux estimator consists of the estimation algorithm of rotor flux position and speed based on the back electromagnetic force (EMF) in order to supply with HRFNN controller. The HRFNN controller consists of the supervisor control, RFNN, and compensated control with adaptive law is applied to PMSM drive system. The parameters of RFNN are trained according to different speeds in electric scooter. The electric scooter is operated to provide disturbance torque. Finally, to show the effectiveness of the proposed controller, comparative studies with PI controller are demonstrated by experimental results.

\section{Configuration of PMSM Drive System}

For convenient analysis, the electric-magnet torque $T_{e}$ equation of PMSM drive electric scooter can be described as [1-3]

$$
T_{e}=\frac{3}{2} \frac{P}{2}\left[L_{m d} I_{f d} i_{q s}+\left(L_{d}-L_{q}\right) i_{d s} i_{q s}\right] .
$$

The equation of the motor dynamics is

$$
T_{e}=T_{L}+B \omega_{r}+J \dot{\omega}_{r}
$$

In (1) and (2), $i_{d s}$ and $i_{q s}$ are $d$ and $q$ axis stator current $L_{d}$ and $L_{q}$ are $d$ - and $q$-axis stator inductance, $\omega_{r}$ is the rotor speed, $P$ is the number of poles, $T_{L}$ stands for the load torque (external load disturbance, e.g., electric scooter), $B$ represents the viscous frictional coefficient, and $J$ is the 


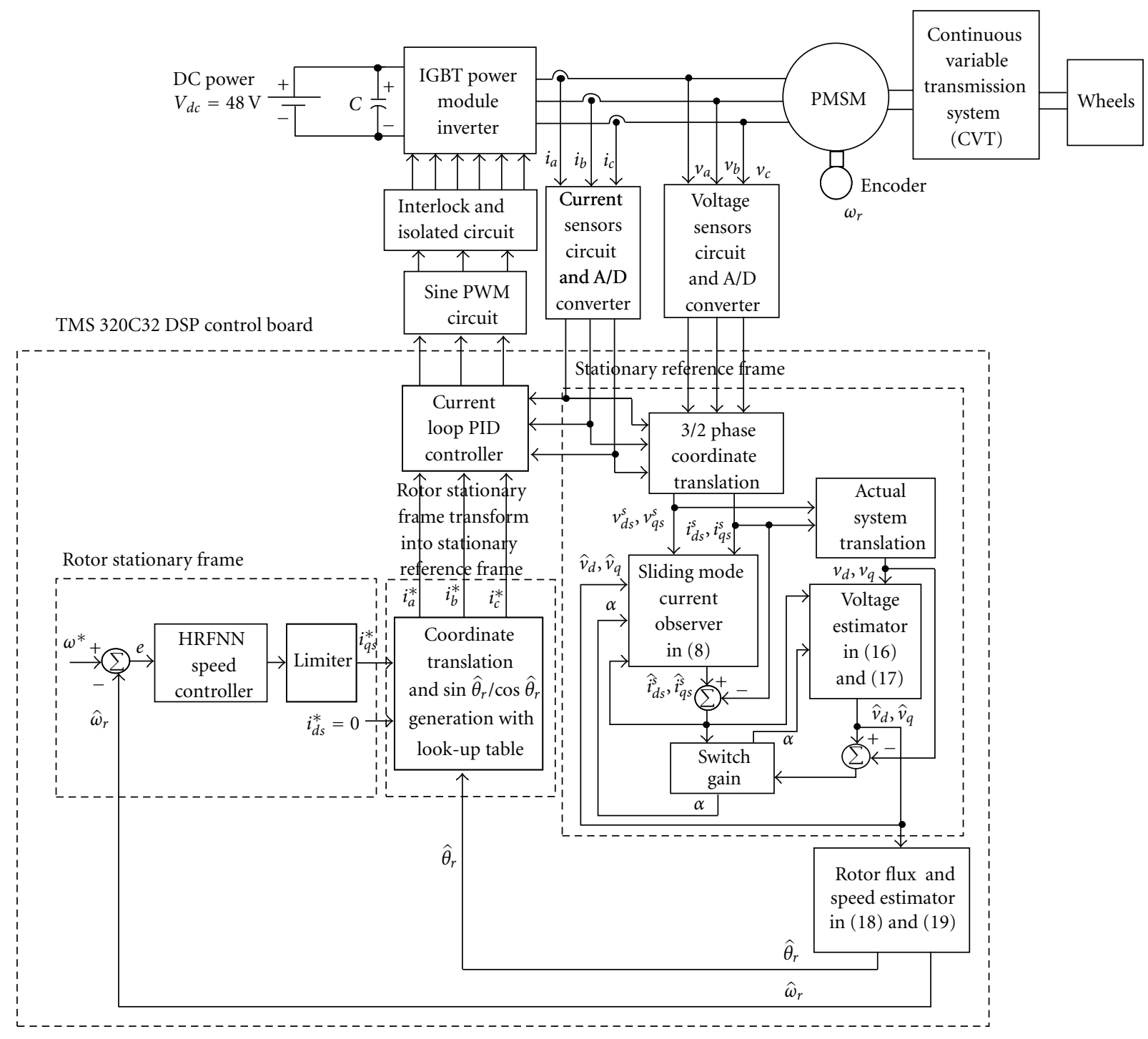

FIGURE 1: Configuration of the proposed HRFNN control system using rotor flux estimator.

moment of inertia. The basic principle in controlling a PM synchronous motor drive is based on field orientation. In (1) and (2), if $i_{d s}=0$, the $d$-axis flux linkage $\lambda_{d}$ is fixed, since $L_{m d}$ and $I_{f d}$ are constant for a PM synchronous motor; the electromagnetic torque $T_{e}$ is then proportional to $i_{q s}$, which is determined by closed-loop control. The rotor flux is produced in the $d$-axis only, while the current vector is generated in the $q$-axis for the field-oriented control. Since the generated motor torque is linearly proportional to the $q$ axis current as the $d$-axis rotor flux is constant in (2), the maximum torque per ampere can be achieved.

With the implementation of field-oriented control, the PM synchronous servo motor drive can be simplified as

$$
T_{e}=K_{t} i_{q s}^{*}, \quad K_{t}=\frac{3 P L_{m d} I_{f d}}{4} .
$$

The block diagram of a PMSM motor drive system for electric scooter is shown in Figure 1. The system is constituted by the following parts: a PMSM (loaded wheel of electric scooter), interlocked and delay time circuits, a fieldoriented mechanism including the coordinate translation and $\sin \left(P \hat{\theta}_{r} / 2\right) / \cos \left(P \hat{\theta}_{r} / 2\right)$ generation, and look-up table generation in order to reduce calculated burden, a hysteresisband comparison current-controlled PWM, a voltage source inverter (VSI), a speed control loop, and a position control loop were implemented by TMS320C32 DSP control board and interface card. The field-oriented mechanism drive system was implemented by TMS320C32 DSP control system. A host PC downloads the program running on the DSP. For the speed control system, the electric scooter is operated to provide constant disturbance torque.

\section{The Hybrid RFNN Control Design Using Rotor Flux Estimator}

The configuration of the proposed HRFNN control system using rotor flux estimator is depicted in Figure 1. 
The HRFNN control system using rotor flux estimator is developed to control PMSM drive system in order to drive electric scooter. The rotor flux estimator consists of the estimation algorithm of rotor flux position and speed based on the back electromagnetic force (EMF). The machine model of a PM synchronous motor can be rewritten in the stationary reference frame as follows [1-3]:

$$
\begin{aligned}
\frac{d}{d t}\left[\begin{array}{l}
i_{d s}^{s} \\
i_{q s}^{s}
\end{array}\right]= & {\left[\begin{array}{cc}
-\frac{R_{s}}{L_{s}} & 0 \\
0 & -\frac{R_{s}}{L_{s}}
\end{array}\right]\left[\begin{array}{l}
i_{d s}^{s} \\
i_{q s}^{s}
\end{array}\right]+\left[\begin{array}{cc}
\frac{1}{L_{s}} & 0 \\
0 & \frac{1}{L_{s}}
\end{array}\right]\left[\begin{array}{c}
v_{d s}^{s} \\
v_{q s}^{s}
\end{array}\right] } \\
& +K_{e}\left[\begin{array}{c}
-\frac{P}{2} \omega_{r} \sin \theta_{r} \\
\frac{P}{2} \omega_{r} \sin \theta_{r}
\end{array}\right],
\end{aligned}
$$

where $v_{d s}^{s}$ and $v_{q s}^{s}$ are $d$ - and $q$-axis stator voltage, $i_{d s}^{s}$ and $i_{q s}^{s}$ are $d$ and $q$ axis stator current, $L_{s}$ is stator inductance, $K_{e}$ stands back electromagnetic force constant, $R_{s}$ represents stator resistance, $\omega_{r}$ is rotor flux speed, and $\theta_{r}$ is rotor flux position. Then back electromagnetic force voltages can be defined as

$$
\left[\begin{array}{l}
v_{d} \\
v_{q}
\end{array}\right]=K_{e}\left[\begin{array}{c}
-\frac{P}{2} \omega_{r} \sin \theta_{r} \\
\frac{P}{2} \omega_{r} \sin \theta_{r}
\end{array}\right] .
$$

Then switching surface of sliding mode can be defined as follows to ensure estimate error between estimate current and measure current reaching on sliding surface:

$$
S=\left[\begin{array}{c}
\hat{i}_{d s}^{s}-i_{d s}^{s} \\
\hat{i}_{q s}^{s}-i_{q s}^{s}
\end{array}\right] \triangleq E_{R}=0 .
$$

The dynamic mode of current observers with sliding mode can be represented as follows to reduce error between estimate current and measure current:

$$
\begin{aligned}
\frac{d}{d t}\left[\begin{array}{c}
\hat{i}_{d s}^{s} \\
\hat{i}_{q s}^{s}
\end{array}\right]= & {\left[\begin{array}{cc}
-\frac{R_{s}}{L_{s}} & 0 \\
0 & -\frac{R_{s}}{L_{s}}
\end{array}\right]\left[\begin{array}{l}
\hat{i}_{d s}^{s} \\
\hat{i}_{q s}^{s}
\end{array}\right]+\left[\begin{array}{cc}
\frac{1}{L_{s}} & 0 \\
0 & \frac{1}{L_{s}}
\end{array}\right]\left[\begin{array}{c}
v_{d s}^{s} \\
v_{q s}^{s}
\end{array}\right] } \\
& +K_{e}\left[\begin{array}{c}
\hat{v}_{d} \\
\hat{v}_{q}
\end{array}\right]+\alpha\left[\begin{array}{l}
\operatorname{sgn}\left(\hat{i}_{d s}^{s}-i_{d s}^{s}\right) \\
\operatorname{sgn}\left(\hat{i}_{q s}^{s}-i_{q s}^{s}\right)
\end{array}\right],
\end{aligned}
$$

where $\hat{i}_{d s}^{s}, \hat{i}_{q s}^{s}$ and $\hat{v}_{d}, \hat{v}_{q}$ represent observational values at $i_{d s}^{s}, i_{q s}^{s}$ and $v_{d}, v_{q}$, respectively, $\alpha$ represents switching gain, $\operatorname{sgn}(\cdot)$ is sign function. Substituting (7) into (4), then the dynamic equations can be acquired as follows:

$$
\dot{E}_{R}=A E_{R}+K_{e}\left[\begin{array}{c}
\hat{v}_{d}-v_{d} \\
\hat{v}_{q}-v_{q}
\end{array}\right]+\alpha\left[\begin{array}{c}
\operatorname{sgn}\left(\hat{i}_{d s}^{s}-i_{d s}^{s}\right) \\
\operatorname{sgn}\left(\hat{i}_{q s}^{s}-i_{q s}^{s}\right)
\end{array}\right],
$$

where

$$
A=\left[\begin{array}{cc}
-\frac{R_{s}}{L_{s}} & 0 \\
0 & -\frac{R_{s}}{L_{s}}
\end{array}\right]
$$

and switching gain $\alpha$ can be designed as

$$
\begin{gathered}
\alpha=\min \left\{R_{s} \frac{\left(\hat{i}_{d s}^{s}-i_{d s}^{s}\right)}{L_{s}}-K_{e}\left(\hat{v}_{d}-v_{d}\right) \operatorname{sgn}\left(\hat{i}_{d s}^{s}-i_{d s}^{s}\right),\right. \\
\left.R_{s} \frac{\left(\hat{i}_{q s}^{s}-i_{q s}^{s}\right)}{L_{s}}-K_{e}\left(\hat{v}_{q}-v_{q}\right) \operatorname{sgn}\left(\hat{i}_{q s}^{s}-i_{q s}^{s}\right)\right\}-\delta,
\end{gathered}
$$

where $\delta$ is very small value to ensure switching gain $\alpha$ action in estimation.

Theorem 1. If switching gain $\alpha$ satisfies (10), then (9) will be guaranteed globally asymptotic stability.

Proof. The Lyapunov function of positive definite can be selected as follows:

$$
V=\frac{1}{2} S^{T} \Gamma_{R} S,
$$

where $\Gamma_{R}$ is unit positive-definite matrix. Then we differentiate (11) as follows:

$$
\begin{aligned}
& \dot{V}=S^{T} \Gamma_{R} \dot{S}=E_{R}^{T} \Gamma_{R}\left\{A E_{R}+K_{e}\left[\begin{array}{c}
\hat{v}_{d}-v_{d} \\
\hat{v}_{q}-v_{q}
\end{array}\right]\right\} \\
& +\alpha E_{R}^{T} \Gamma_{R}\left[\begin{array}{c}
\operatorname{sgn}\left(\hat{i}_{d s}^{s}-i_{d s}^{s}\right) \\
\operatorname{sgn}\left(\hat{i}_{q s}^{s}-i_{q s}^{s}\right)
\end{array}\right]
\end{aligned}
$$

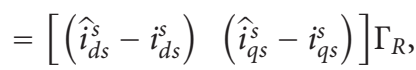

$$
\begin{aligned}
& \times\left[\begin{array}{c}
-R_{s} \frac{\left(\hat{i}_{d s}^{s}-i_{d s}^{s}\right)}{L_{s}}+K_{e}\left(\hat{v}_{d}-v_{d}\right)+\alpha \operatorname{sgn}\left(\hat{i}_{d s}^{s}-i_{d s}^{s}\right) \\
-R_{s} \frac{\left(\hat{i}_{q s}^{s}-i_{q s}^{s}\right)}{L_{s}}+K_{e}\left(\hat{v}_{q}-v_{q}\right)+\alpha \operatorname{sgn}\left(\hat{i}_{q s}^{s}-i_{q s}^{s}\right)
\end{array}\right] \\
& =-\frac{R_{s}}{L_{s}}\left[\left(\hat{i}_{d s}^{s}-i_{d s}^{s}\right)^{2}+\left(\hat{i}_{q s}^{s}-i_{q s}^{s}\right)^{2}\right] \\
& +K_{e}\left[\left(\hat{v}_{d}-v_{d}\right)\left(\hat{i}_{d s}^{s}-i_{d s}^{s}\right)+\left(\hat{v}_{q}-v_{q}\right)\left(\hat{i}_{q s}^{s}-i_{q s}^{s}\right)\right] \\
& +\alpha\left[\left|\hat{i}_{d s}^{s}-i_{d s}^{s}\right|+\left|\hat{i}_{q s}^{s}-i_{q s}^{s}\right|\right] \\
& \underline{\underline{\Delta}} \lambda_{1}+\lambda_{2} \text {, }
\end{aligned}
$$

where

$$
\begin{aligned}
& \lambda_{1}=-\frac{R_{s}}{L_{s}}\left(\hat{i}_{d s}^{s}-i_{d s}^{s}\right)^{2}+K_{e}\left(\hat{v}_{d}-v_{d}\right)\left(\hat{i}_{d s}^{s}-i_{d s}^{s}\right)+\alpha\left|\hat{i}_{d s}^{s}-i_{d s}^{s}\right|, \\
& \lambda_{2}=-\frac{R_{s}}{L_{s}}\left(\hat{i}_{q s}^{s}-i_{q s}^{s}\right)^{2}+K_{e}\left(\hat{v}_{q}-v_{q}\right)\left(\hat{i}_{q s}^{s}-i_{q s}^{s}\right)+\alpha\left|\hat{i}_{q s}^{s}-i_{q s}^{s}\right| .
\end{aligned}
$$

If the differentiation of the Lyapunov function is negative definite, the system can be guaranteed globally asymptotic stability. By switching gain in (9), $\lambda_{1}$ and $\lambda_{2}$ in (13) should be less than zero, then $\dot{V}<0$ satisfy switching condition of sliding mode.

According to Theorem 1, the switching gain of switching surface in equal control of sliding mode is small enough, so 


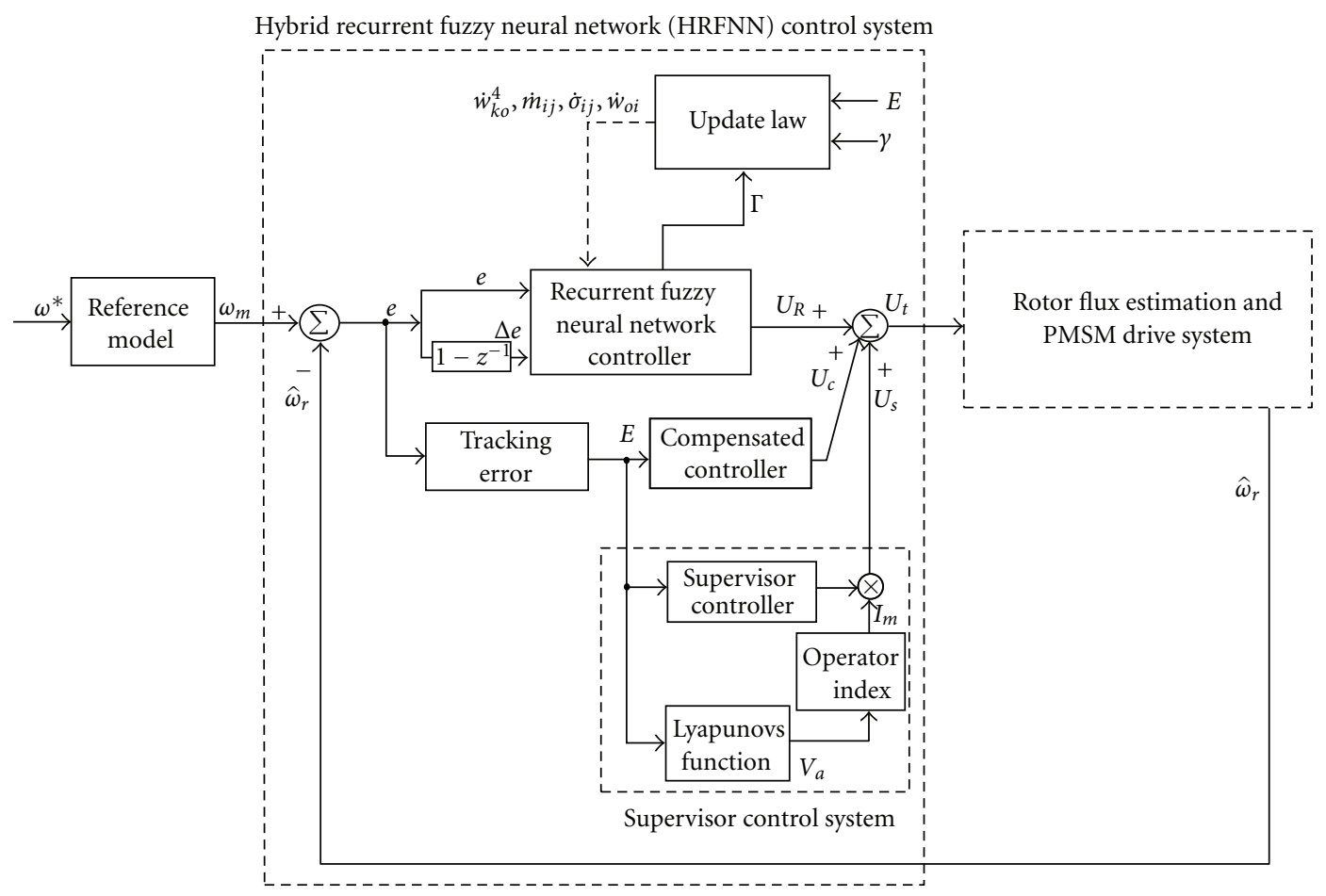

FIGURE 2: The block diagram of HRFNN control system using rotor flux estimation.

that switching condition can be satisfied. When switching condition can be satisfied, the system in (8) will achieve asymptotic stability. Therefore,

$$
\dot{E}_{R}=0 .
$$

It represent that system dynamic fall onto switching surface. We use (8) and (14), and relationship can be acquired as

$$
\begin{aligned}
& \hat{v}_{d}=v_{d}-\frac{\alpha}{K_{e}} \operatorname{sgn}\left(\hat{i}_{d s}^{s}-i_{d s}^{s}\right), \\
& \hat{v}_{q}=v_{q}-\frac{\alpha}{K_{e}} \operatorname{sgn}\left(\hat{i}_{q s}^{s}-i_{q s}^{s}\right) .
\end{aligned}
$$

We substitute (15) into (5), then rotor flux position $\theta_{r}$ of motor can be replaced into $\hat{\theta}_{r}$, and it is can be estimated as

$$
\hat{\theta}_{r}=\tan ^{-1}\left(-\hat{v}_{d}\right)=\tan ^{-1}\left\{\frac{-K_{e} v_{d}+\alpha \operatorname{sgn}\left(\hat{i}_{d s}^{s}-i_{d s}^{s}\right)}{K_{e} v_{q}-\alpha \operatorname{sgn}\left(\hat{i}_{q s}^{s}-i_{q s}^{s}\right)}\right\},
$$

and rotor angular speed $\omega_{r}$ of motor can be estimated as

$$
\hat{\omega}_{r}=\frac{2}{P}\left(\hat{v}_{q} \cos \hat{\theta}_{r}-\hat{v}_{d} \sin \hat{\theta}_{r}\right),
$$

where $\hat{\theta}_{r}$ iss estimation of rotor flux position $\theta_{r}$ and $\hat{\omega}_{r}$ is estimation of rotor angular speed $\omega_{r}$.

In order to avoid chattering phenomenon of sliding mode, the sign function $\operatorname{sgn}(f(t))$ can be replaced by the following equation as

$$
\frac{f(t)}{|f(t)|+\sigma}
$$

where

$$
\sigma= \begin{cases}\sigma_{0}, & |f(t)|<\varepsilon \\ 0, & |f(t)| \geq \varepsilon\end{cases}
$$

where $\sigma_{0}$ and $\varepsilon$ are positive constants.

Owing to the load of electric scooter exited many uncertainties. The conditional PID controller cannot process with nonlinear uncertainties such as electric scooter. Therefore, an HRFNN control system using rotor flux estimator was developed to control PMSM drive system in order to drive electric scooter in this section. The configuration of the proposed HRFNN control system, which combines a supervisory control system, RFNN controller, and compensated control system, is depicted in Figure 2. The control law is designed to take the following form [6]:

$$
U_{t}=U_{S}+U_{R}+U_{C},
$$

where $U_{S}$ is a supervisory control, $U_{R}$ is a RFNN control, and $U_{C}$ is a compensated control. The supervisory control $U_{S}$ is designed so that the states of the controlled system are stabilized around a predetermined bound region. Due to the excessive and chattering control effort induced by the supervisory control law, the RFNN control and compensated control are introduced to reduce and smooth the control effort when the system states are inside the predefined bound region. The RFNN control $U_{R}$ is the main tracking controller used to mimic an idea control law, and the compensated control $U_{C}$ is designed to compensate the difference between the idea control law and the RFNN control. The supervisory control law fires only when the RFNN approximation properties cannot be guaranteed. 
A four-layer RFNN comprises the input (the $i$ layer), membership (the $j$ layer), rule (the $k$ layer), and output layer (the $o$ layer) and is adopted to implement the RFNN controller in this study. The signal propagation and the basic function in each layer of the RFNN are introduced as follows.

Layer 1 (Input Layer). For every node $i$ in this layer, the net input and the net output are represented as

$$
\begin{aligned}
& \operatorname{net}_{i}^{1}(N)=\prod_{o} x_{i}^{1}(N) w_{o i} y_{o}^{4}(N-1), \\
& y_{i}^{1}(N)=f_{i}^{1}\left(\operatorname{net}_{i}^{1}(N)\right)=\operatorname{net}_{i}^{1}(N), \\
& i=1,2,
\end{aligned}
$$

where $x_{1}^{1}=\omega^{*}-\widehat{\omega}_{r}$ is the command error between the desired command, $\omega^{*}$, and the estimation of rotor angular speed, $\hat{\omega}_{r} ; x_{2}^{1}=e\left(1-z^{-1}\right) \equiv \Delta e$ is the command error change, in which $z^{-1}$ represents a time delay; $N$ denotes the number of iterations; $y_{o}^{4}$ is the output of the RFNN.

Layer 2 (Membership Layer). In this layer, each node performs a membership function. The Gaussian function is adopted as the membership function. For the $j$ th node,

$$
\begin{aligned}
& \operatorname{net}_{j}^{2}(N)=-\frac{\left(x_{i}^{2}-m_{i j}\right)^{2}}{\left(\sigma_{i j}\right)^{2}}, \\
& y_{j}^{2}(N)=f_{j}^{2}\left(\operatorname{net}_{j}^{2}(N)\right)=\exp \left(\operatorname{net}_{j}^{2}(N)\right), \\
& j=1, \ldots, n,
\end{aligned}
$$

where $m_{i j}$ and $\sigma_{i j}$ are, respectively, the mean and the standard deviation of the Gaussian function in the $j$ th term of the $i$ th input linguistic variable $x_{i}^{2}$ to the node of Layer 2, and $n$ is the total number of the linguistic variables with respect to the input nodes.

Layer 3 (Rule Layer). Each node $k$ in this layer is denoted by $\prod$, which multiplies the input signals and outputs the result of product. For the $k$ th rule node

$$
\begin{array}{rl}
\operatorname{net}_{k}^{3}(N) & =\prod_{j} w_{j k}^{3} x_{j}^{3}(N), \\
y_{k}^{3}(N) & =f_{k}^{3}\left(\operatorname{net}_{k}^{3}(N)\right)=\operatorname{net}_{k}^{3}(N), \\
k & k=1, \ldots, l,
\end{array}
$$

where $x_{j}^{3}$ represents the $j$ th input to the node of Layer $3 ; w_{j k}^{3}$, the weights between the membership layer and the rule layer, are assumed to be unity; $l=(n / i)^{i}$ is the number of rules with complete rule connection if each input node has the same linguistic variables.
Layer 4 (Output Layer). The single node $o$ in this layer is labeled with $\sum$, which computes the overall output as the summation of all input signals:

$$
\begin{aligned}
& \operatorname{net}_{o}^{4}(N)=\sum_{k} w_{k o}^{4} x_{k}^{4}(N), \\
& y_{o}^{4}(N)=f_{o}^{4}\left(\operatorname{net}_{o}^{4}(N)\right)=\operatorname{net}_{o}^{4}(N), \\
& \qquad o=1,
\end{aligned}
$$

where the connecting weight $w_{k o}^{4}$ is the output action strength of the oth output associated with the $k$ th rule; $x_{k}^{4}$ represents the $k$ th input to the node of Layer $4, y_{o}^{4}=U_{R}$. Moreover, $U_{R}$ can be rewritten as follows:

$$
U_{R}=U_{R}(\mathbf{E} \mid O)=O^{T} \Gamma,
$$

where the error signal $\mathbf{E}$ is the input of the RFNN; $O=$ $\left[\begin{array}{llll}w_{11}^{4} & w_{21}^{4} & \cdots & w_{l 1}^{4}\end{array}\right]^{T}$ is the adjustable parameter vector of the RFNN; $\Gamma=\left[\begin{array}{llll}x_{1}^{4} & x_{2}^{4} & \cdots & x_{l}^{4}\end{array}\right]^{T}$, in which $x_{k}^{4}$ is determined by the selected membership function and $0 \leq$ $x_{k}^{4} \leq 1$.

To develop the compensated control $U_{C}$, a minimum approximation error $\rho$ is defined as follows:

$$
\rho=U^{*}-U_{R}\left(\mathbf{E} \mid O^{*}\right),
$$

where $O^{*}$ is an optimal weight vector which achieves the minimum approximation error, and the absolute value of $\rho$ is assumed to be less than a small positive constant, $\eta$ (i.e., $|\rho|<\eta)$. The error equation can be rewritten as follows:

$$
\begin{aligned}
\dot{\mathbf{E}} & =\Lambda \mathbf{E}+\mathbf{B}_{m}\left\{\left[U^{*}-U_{R}(\mathbf{E} \mid O)\right]-U_{C}-U_{S}\right\} \\
& =\Lambda \mathbf{E}+\mathbf{B}_{m}\left\{\left[U^{*}-U_{R}\left(\mathbf{E} \mid O^{*}\right)+U_{R}\left(\mathbf{E} \mid O^{*}\right)-U_{R}(\mathbf{E} \mid O)\right]\right. \\
& \left.\quad-U_{C}-U_{S}\right\} \\
& =\Lambda \mathbf{E}+\mathbf{B}_{m}\left\{\left[U^{*}-U_{R}\left(\mathbf{E} \mid O^{*}\right)+\left(O^{*}\right) \Gamma-(O) \Gamma\right]-U_{C}-U_{S}\right\} \\
= & \Lambda \mathbf{E}+\mathbf{B}_{m}\left\{\rho+\left(O^{*}-O\right)^{T} \Gamma-U_{C}-U_{S}\right\} .
\end{aligned}
$$

Then, the Lyapunov function is defined as

$$
V_{a}(t)=\frac{1}{2} \mathbf{E P E}+\frac{1}{2 \gamma}\left\{O^{*}-O\right\}^{T}\left\{O^{*}-O\right\} .
$$

Take the derivative of the Lyapunov function and use (27), then

$$
\begin{aligned}
\dot{V}_{a}(t)= & -\frac{1}{2} \mathbf{E Q E}+\mathbf{E}^{T} \mathbf{P} \mathbf{B}_{m}\left\{\eta-U_{C}-U_{S}\right\} \\
& +\mathbf{E}^{T} \mathbf{P} \mathbf{B}_{m}\left\{O^{*}-O\right\}^{T} \Gamma-\frac{1}{\gamma}\left\{O^{*}-O\right\}^{T} \dot{O} .
\end{aligned}
$$

To satisfy $\dot{V}_{a}(t) \leq 0$, the adaptation laws $\dot{O}$ and the compensated controller $U_{C}$ are designed as follows:

$$
\begin{gathered}
\dot{O}=\gamma \mathbf{E}^{T} \mathbf{P} \mathbf{B}_{m} \Gamma, \\
U_{C}=\eta \operatorname{sgn}\left(\mathbf{E}^{T} \mathbf{P} \mathbf{B}_{m}\right),
\end{gathered}
$$


where $\gamma>0$ is denoted as adaptation gains. Substitute (30) into (29), then

$$
\begin{aligned}
\dot{V}_{a}(t) & =-\frac{1}{2} \mathbf{E Q E}+\mathbf{E}^{T} \mathbf{P B}_{m}\left\{\eta-U_{C}-U_{S}\right\} \\
& \leq-\frac{1}{2} \mathbf{E Q E}+\mathbf{E}^{T} \mathbf{P B}_{m}\left\{\eta-U_{C}-U_{S}\right\} \\
& \leq-\frac{1}{2} \mathbf{E Q E}+\mathbf{E}^{T} \mathbf{P B}_{m}|\eta|-\mathbf{E}^{T} \mathbf{P B}_{m} U_{C}-\mathbf{E}^{T} \mathbf{P B}_{m} U_{S} .
\end{aligned}
$$

The supervisory controller $U_{S}$ is designed as follows:

$$
U_{S}=\mathbf{I}_{m} \operatorname{sgn}\left(\mathbf{E}^{T} \mathbf{P} \mathbf{B}_{m}\right)
$$

where

$$
\mathbf{I}_{m}= \begin{cases}1, & \text { if } V_{a}>\bar{V} \\ 0, & \text { if } V_{a}<\bar{V}\end{cases}
$$

Substitute (31) and (33) into (32), thus

$$
\dot{V}_{a}(t) \leq-\frac{1}{2} \mathbf{E}^{T} \mathbf{Q E} \leq 0 .
$$

Since $\dot{V}_{a}(t) \leq 0, \dot{V}_{a}(t)$ is negative semidefinite (i.e., $V_{a}(t) \leq$ $\left.V_{a}(0)\right)$, which implies $\mathbf{E}$ and $\left(O^{*}-O\right)$ are bounded. Let function $\Xi(t)=-\dot{V}_{a}(t)=\mathbf{E}^{T} \mathbf{Q E} / 2$, and integrate function $\Xi(t)$ with respect to time:

$$
\int_{0}^{t} \Xi(t) d \tau=V_{a}(0)-V_{a}(t)
$$

Because $V_{a}(0)$ is bounded and $V_{a}(t)$ is nonincreasing and bounded, then

$$
\lim _{t \rightarrow \infty} \int_{0}^{t} \Xi(t) d \tau<\infty .
$$

Differentiate $\Xi(t)$ with respect to time, then

$$
\dot{\Xi}(t)=\mathbf{E}^{T} \mathbf{Q} \dot{\mathbf{E}} .
$$

Since all the variables in the right side of (28) are bounded, it implies $\dot{\mathbf{E}}$ is also bounded. Then $\Xi(t)$ is uniformly continuous [23]. By using Barbalat's lemma [23, 24], it can be shown that $\lim _{t \rightarrow \infty} \Xi(t)=0$. Therefore, $\mathbf{E}(t) \rightarrow 0$ as $t \rightarrow \infty$. As a result, the hybrid control system is asymptotically stable. Moreover, the tracking error of the system, $e$, will converge to zero according to $\mathbf{E}(t)=0$.

In order to train the RFNN effectively, an online parameter training methodology can be derived using adaptation laws $\dot{O}$ of the above Lyapunov stability theorem. Then adaptation laws of the parameters in the RFNN $\dot{O}\left(w_{k o}^{4}, m_{i j}, \sigma_{i j}, w_{o i}\right)$ can be computed by the gradient descent method and the backpropagation algorithm as follows:

$$
\begin{aligned}
\dot{w}_{k o}^{4} & =\gamma \mathbf{E}^{T} \mathbf{P B}_{m} \Gamma \\
& \triangleq-\gamma \frac{\partial V_{a}}{\partial U_{R}} \frac{\partial U_{R}}{\partial y_{o}^{4}} \frac{\partial y_{o}^{4}}{\partial \operatorname{net}_{o}^{4}} \frac{\partial \text { net }_{o}^{4}}{\partial w_{k o}^{4}} \\
& =-\gamma \frac{\partial V_{a}}{\partial U_{R}} x_{k}^{4} .
\end{aligned}
$$

The above Jacobian term of controlled system can be rewritten as $\partial V_{a} / \partial U_{R}=-\mathbf{E}^{T} \mathbf{P} \mathbf{B}_{m}$. The error term can be calculated as

$$
\delta_{k}^{3} \triangleq-\frac{\partial V_{a}}{\partial U_{R}} \frac{\partial U_{R}}{\partial y_{o}^{4}} \frac{\partial y_{o}^{4}}{\partial \operatorname{net}_{o}^{4}} \frac{\partial \text { net }_{o}^{4}}{\partial y_{k}^{3}} \frac{\partial y_{k}^{3}}{\partial \text { net }_{k}^{3}}=\mathbf{E}^{T} \mathbf{P B}_{m} w_{k o}^{4} .
$$

The error term of membership function can be calculated as

$$
\begin{aligned}
\delta_{j}^{2} & \triangleq-\frac{\partial V_{a}}{\partial U_{R}} \frac{\partial U_{R}}{\partial y_{o}^{4}} \frac{\partial y_{o}^{4}}{\partial \operatorname{net}_{o}^{4}} \frac{\partial \operatorname{net}_{o}^{4}}{\partial y_{k}^{3}} \frac{\partial y_{k}^{3}}{\partial \operatorname{net}_{k}^{3}} \frac{\partial \operatorname{net}_{k}^{3}}{\partial y_{j}^{2}} \frac{\partial y_{j}^{2}}{\partial \operatorname{net}_{j}^{2}} \\
& =\sum_{k} \delta_{k}^{3} y_{k}^{3}(N) .
\end{aligned}
$$

The mean $m_{i j}$ and standard deviation $\sigma_{i j}$ of the Gauss function can be updated using the gradient descent method as

$$
\begin{gathered}
\dot{m}_{i j}=-\frac{\partial V_{a}}{\partial \operatorname{net}_{j}^{2}} \frac{\partial \operatorname{net}_{j}^{2}}{\partial m_{i j}}=\delta_{j}^{2} \frac{2\left(x_{i}^{2}-m_{i j}\right)}{\left(\sigma_{i j}\right)^{2}}, \\
\dot{\sigma}_{i j}=\frac{\partial V_{a}}{\partial \operatorname{net}_{j}^{2}} \frac{\partial \operatorname{net}_{j}^{2}}{\partial \sigma_{i j}}=\delta_{j}^{2} \frac{2\left(x_{i}^{2}-m_{i j}\right)^{2}}{\left(\sigma_{i j}\right)^{3}} .
\end{gathered}
$$

The recurrent weight $w_{o i}$ can be updated as

$$
\begin{aligned}
\dot{w}_{o i} & =-\frac{\partial V_{a}}{\partial \operatorname{net}_{j}^{2}} \frac{\partial \text { net }_{j}^{2}}{\partial y_{i}^{1}} \frac{\partial y_{i}^{1}}{\partial \text { net }_{i}^{1}} \frac{\partial \text { net }_{i}^{1}}{\partial w_{o i}} \\
& =\sum_{j} \delta_{j}^{2} \frac{2\left(m_{i j}-x_{i}^{2}(N)\right)}{\left(\sigma_{i j}\right)^{2}} x_{i}^{1}(N) y_{o}^{4}(N-1) .
\end{aligned}
$$

\section{Experimental Results}

A block diagram of the DSP-based computer control system for a PMSM servo drive is depicted in Figure 1. The current-controlled PWM VSI is implemented by the IGBT power modules with a switching frequency of $15 \mathrm{kHz}$. The control algorithm was implemented by a TMS320C32 DSPbased control system. A TMS320C32 DSP-based control board includes multichannels of D/A, eight channels programmable PWM and encoder interface circuits. The PMSM used in this drive system is a three-phase two-pole $48 \mathrm{~V}$ $750 \mathrm{~W} 16.5$ A $3600 \mathrm{rpm}$ type. The parameters of the PMSM are given as follows: $R_{s}=2.5 \Omega, \bar{J}=2.15 \times 10^{-3} \mathrm{Nms}, \bar{B}=$ $6.18 \times 10^{-3} \mathrm{~N} \mathrm{~m} \mathrm{~s} / \mathrm{rad}, K_{t}=0.86 \mathrm{~N} \mathrm{~m} / \mathrm{A}, L_{d}=L_{q}=6.53 \mathrm{mH}$ throught open circuit test, short test, rotor block test, loading test.

The control gains of the proposed HRFNN control system using rotor flux estimation are given for the following:

$$
\begin{gathered}
\delta=0.1, \quad \alpha=2.5, \quad \varepsilon=0.6, \\
\gamma=0.5, \quad \eta=0.1, \quad \sigma=28, \quad \rho=0.05 .
\end{gathered}
$$

All the gains in the HRFNN control system using rotor flux estimation are chosen to achieve the best transient 


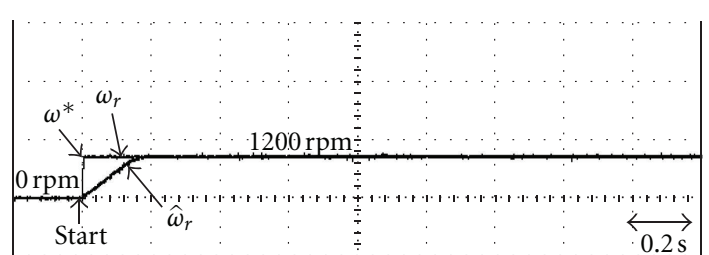

(a)

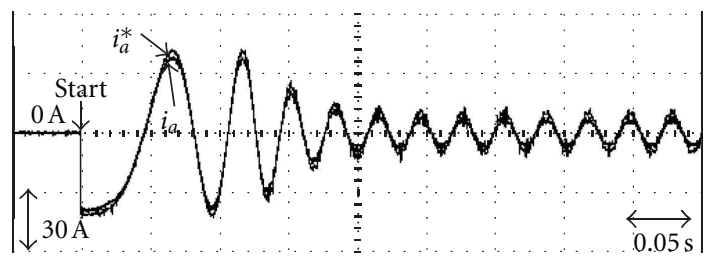

(c)

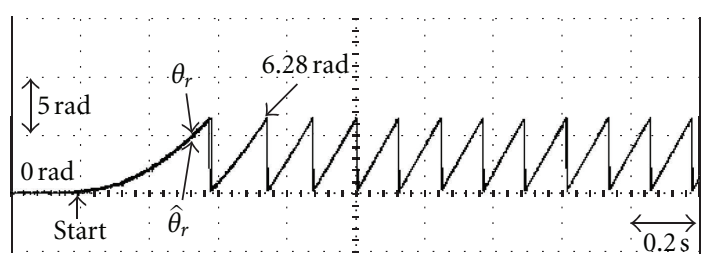

(b)

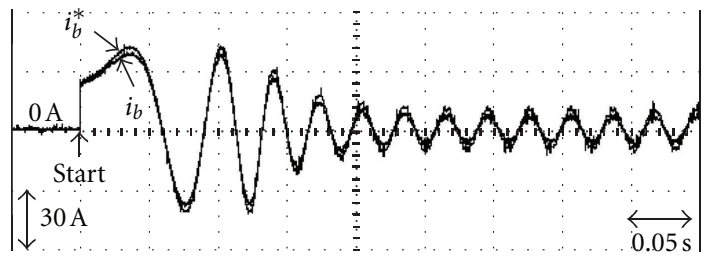

(d)

FIGURE 3: Experimental results of PI control system with mounted electric scooter at $1200 \mathrm{rpm}$ : (a) command rotor speed $\omega^{*}$, measure rotor speed $\omega_{r}$, and estimate rotor speed $\hat{\omega}_{r} ;(\mathrm{b})$ measure rotor position $\theta_{r}$ and estimate rotor position $\hat{\theta}_{r} ;(\mathrm{c})$ command current $i_{a}^{*}$ and measure current $i_{a}$ in phase $a$; (d) command current $i_{b}^{*}$ and measure current $i_{b}$ in phase $b$.

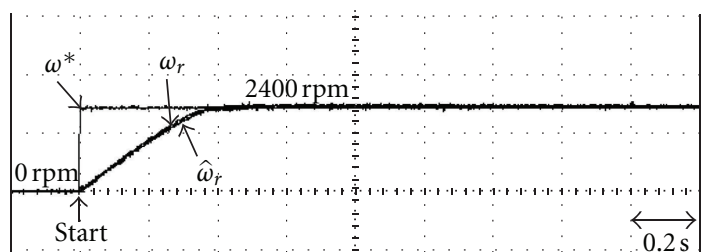

(a)

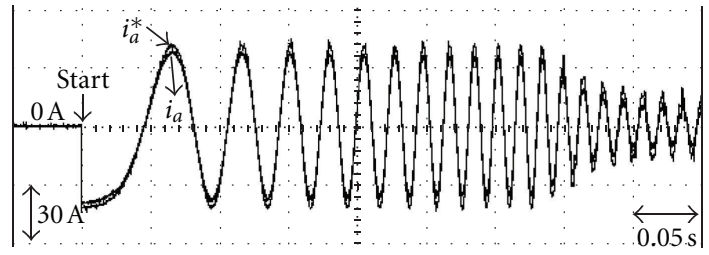

(c)

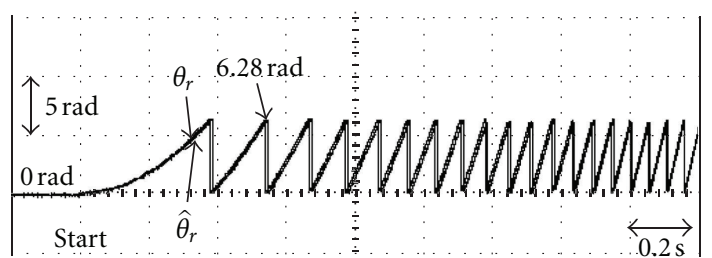

(b)

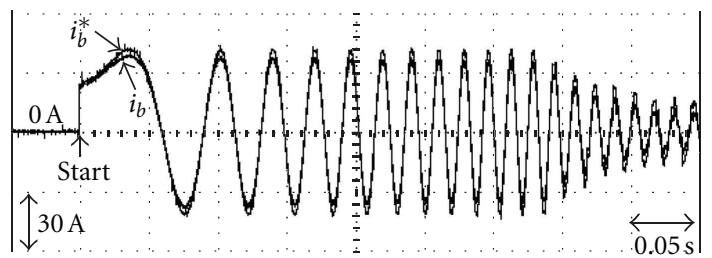

(d)

FIGURE 4: Experimental results of PI control system with mounted electric scooter at $2400 \mathrm{rpm}$ : (a) command rotor speed $\omega^{*}$, measure rotor speed $\omega_{r}$ and estimate rotor speed $\widehat{\omega}_{r} ;(\mathrm{b})$ measure rotor position $\theta_{r}$ and estimate rotor position $\hat{\theta}_{r} ;(\mathrm{c})$ command current $i_{a}^{*}$ and measure current $i_{a}$ in phase $a$; (d) command current $i_{b}^{*}$ and measure current $i_{b}$ in phase $b$.

control performance in experimentation considering the requirement of stability. To show the effectiveness of the RFNN control with small rule set, the RFNN has two, six, nine, and one neuron at the input, membership, rule, and output layers, respectively. It can be regarded that the associated fuzzy sets with the Gaussian function for each input signal are divided into $\mathrm{N}$ (negative), $\mathrm{Z}$ (zero), and $\mathrm{P}$ (positive). Usually, some heuristics can be used to roughly initialize the parameters of the RFNN for practical applications. The effect due to the inaccurate selection of the initialized parameters can be retrieved by the online parameter training methodology. Therefore, for simplicity, the means of the Gaussian functions are set at $-1,0,1$ for the $\mathrm{N}, \mathrm{Z}, \mathrm{P}$ neurons, and the standard deviations of the Gaussian functions are set at 1 . Moreover, the connecting weights between the output layer and rule layer, and the recurrent weights are initialized with random number.

To show the advantages of the HRFNN control PMSM drive system using rotor flux estimator for electric scooter is experimented for comparison. Two conditions provided in the experimentation here, one being the $1200 \mathrm{rpm}$ case with mounted electric scooter and another being the $2400 \mathrm{rpm}$ case with mounted electric scooter, are depicted in Figures 3 and 4, respectively. The measure and estimate rotor speed responses, measure and estimate rotor position, command and measure current in phase (a), and command and measure current in phase of the PI control system with mounted electric scooter at $1200 \mathrm{rpm}$ are depicted in Figures 3(a), 


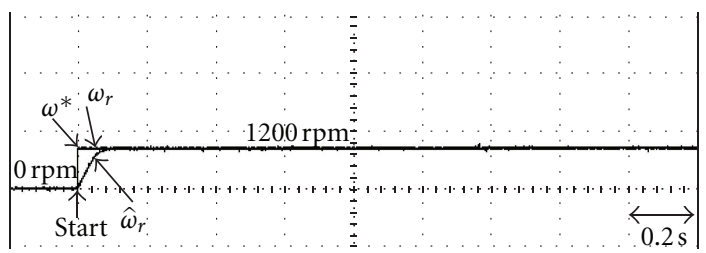

(a)

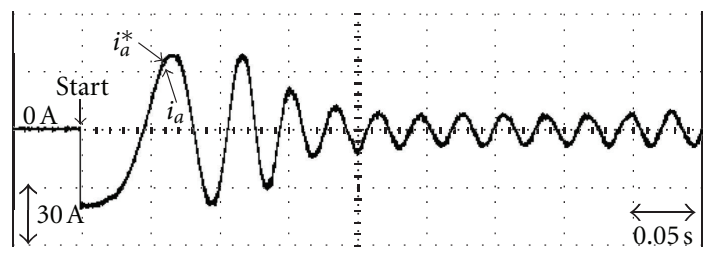

(c)

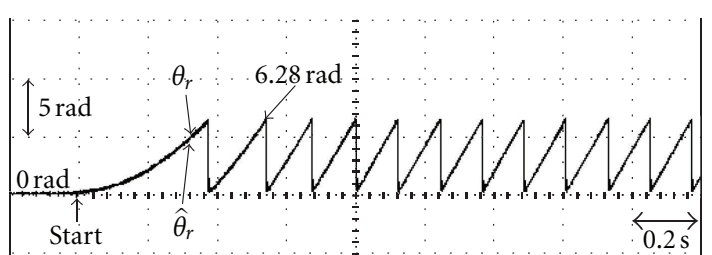

(b)

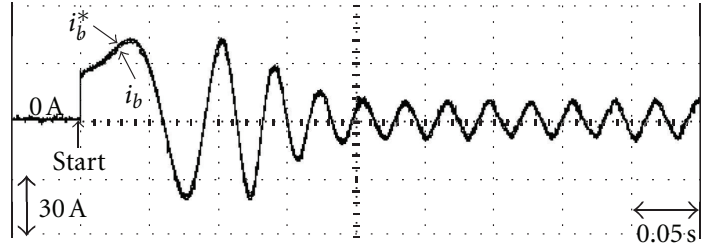

(d)

FIGURE 5: Experimental results of HRFNN control system with mounted electric scooter at $1200 \mathrm{rpm}$ : (a) command rotor speed $\omega^{*}$, measure rotor speed $\omega_{r}$, and estimate rotor speed $\hat{\omega}_{r}$; (b) measure rotor position $\theta_{r}$ and estimate rotor position $\hat{\theta}_{r}$; (c) command current $i_{a}^{*}$ and measure current $i_{a}$ in phase $a$; (d) command current $i_{b}^{*}$ and measure current $i_{b}$ in phase $b$.

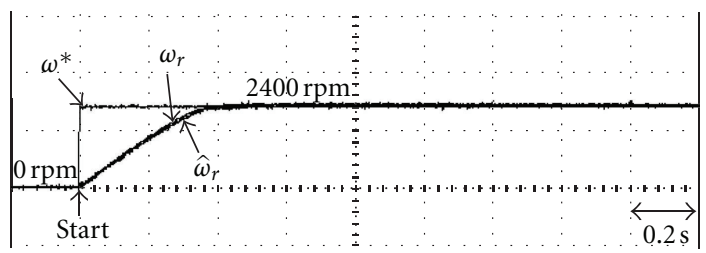

(a)

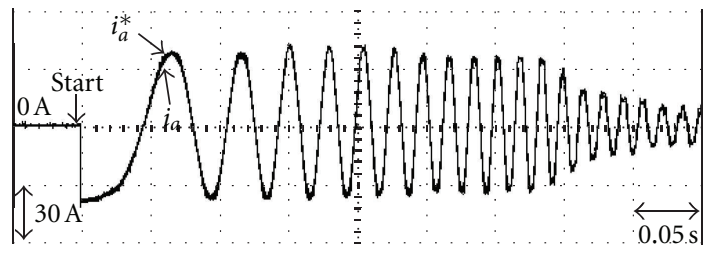

(c)

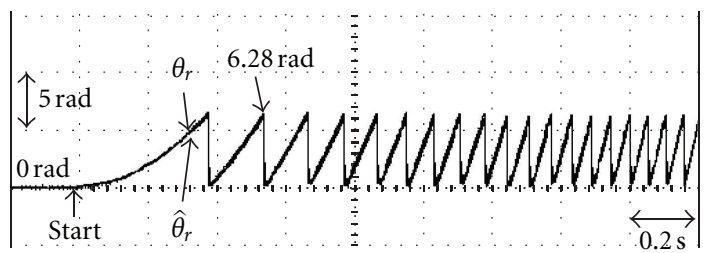

(b)

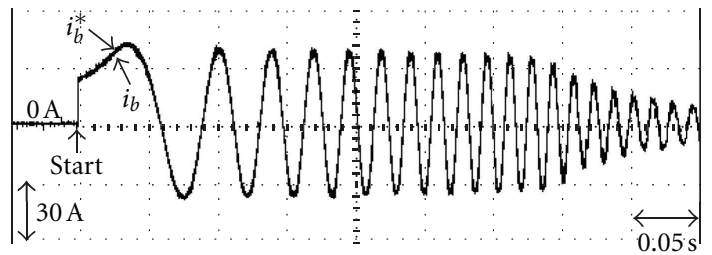

(d)

FIGURE 6: Experimental results of HRFNN control system with mounted electric scooter at $2400 \mathrm{rpm}$ : (a) command rotor speed $\omega^{*}$, measure rotor speed $\omega_{r}$, and estimate rotor speed $\widehat{\omega}_{r} ;(\mathrm{b})$ measure rotor position $\theta_{r}$ and estimate rotor position $\hat{\theta}_{r}$; (c) command current $i_{a}^{*}$ and measure current $i_{a}$ in phase $a$; (d) command current $i_{b}^{*}$ and measure current $i_{b}$ in phase $b$.

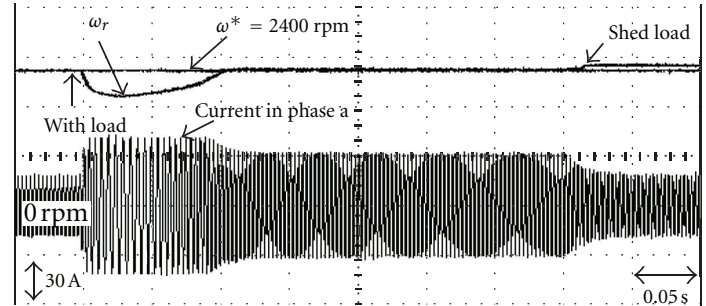

(a)

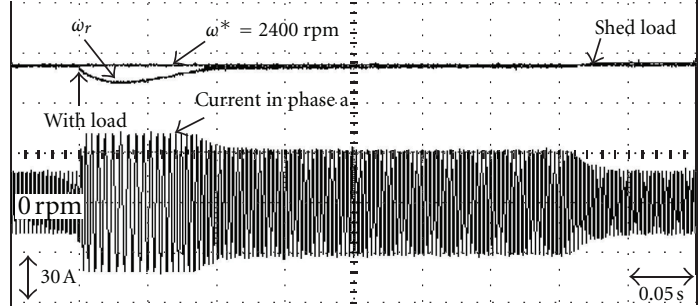

(b)

Figure 7: Experimental results due to a $T_{L}=2 \mathrm{Nm}$ load torque disturbance with load and shed load at $2400 \mathrm{rpm}$ : (a) command rotor speed $\omega^{*}$, measure rotor speed $\omega_{r}$, and measure current $i_{a}$ in phase $a$ using a PI control system; (b) command rotor speed $\omega^{*}$, measure rotor speed $\omega_{r}$, and measure current $i_{a}$ in phase $a$ using HRFNN control system. 
3(b), 3(c), and 3(d), respectively. The measure and estimate rotor speed responses, measure and estimate rotor position, command and measure current in phase (a), command and measure current in phase of the PI control system with mounted electric scooter at $2400 \mathrm{rpm}$ are depicted in Figures 4(a), 4(b), 4(c), and 4(d), respectively. Due to PI control system cannot process nonlinear uncertainties. The degenerate tracking responses shown in Figure 4(a) are resulted owing to the conditions of parameter variation and external disturbance.

The experimental results of the HRFNN control system with mounted electric scooter at $1200 \mathrm{rpm}$ case and $2400 \mathrm{rpm}$ case are shown in Figures 5 and 6. The measure and estimate rotor speed responses, measure and estimate rotor position, command and measure current in phase (a), command and measure current in phase of the HRFNN control system with mounted electric scooter at $1200 \mathrm{rpm}$ are shown in Figures 5(a), 5(b), 5(c), and 5(d), respectively. The measure and estimate rotor speed responses, measure and estimate rotor position, command and measure current in phase (a), command and measure current in phase of the HRFNN control system with mounted electric scooter at $2400 \mathrm{rpm}$ are shown in Figures 6(a), 6(b), 6(c), and $6(\mathrm{~d})$, respectively. However, owing to the online adaptive mechanism of RFNN and the compensated controller, accurate tracking control performance of the PMSM can be obtained. The control performance of the proposed HRFNN control system is superior than PI control system with mounted electric scooter. Additionally, the small chattering phenomena, existed in phase (a) and in phase (b) as shown in Figures 6(c) and 6(d), are owing to the online adjusting of the RFNN to cope with the high-frequency unmodelled dynamic of the controlled plant. From the experimental results, the control performance of the proposed the HRFNN controller using rotor flux estimator is suitable for PMSM drive in electric scooter. The measured rotor speed responses due to step disturbance torque are given finally. The measured rotor speed responses and measure current in phase (a) due to a $T_{L}=2 \mathrm{Nm}$ load torque disturbance with load and shed load using the PI control system at $2400 \mathrm{rpm}$ are shown in Figure 7(a), and the measured speed responses at the same disturbance condition using HRFNN control system are shown in Figure 7(b). From the experimental results, the degenerated responses due to the variation of rotor inertia and load torque disturbance are much improved using the HRFNN control system. From experimental results, transient response of the HRFNN control system is better than PI control system at load regulation.

\section{Conclusions}

A permanent magnet synchronous motor (PMSM) drive system using hybrid recurrent fuzzy neural network (HRFNN) control system with rotor flux estimator has been successfully developed to drive electric scooter with robust control characteristics in this study. First, the dynamic models of a PMSM drive system were derived according to electric scooter. Owing to the load of electric scooter exited many uncertainties. The conditional PI controller cannot process with nonlinear uncertainties such as electric scooter. Next, an HRFNN control system with supervisory control was designed based on the uncertainty bounds of the controlled system to stabilize the system states around a predefined bound region. To reduce the excessive and chattering control efforts resulted by the supervisory control, RFNN and compensated control system were introduced to reduce and smooth the control effort when the system states were inside the predefined bound region. Moreover, an online parameter training methodology, which was derived using the Lyapunov stability theorem and the gradient descent method, was proposed to increase the online learning capability of the RFNN. In order to reduce interference of encoder and cost down, a HRFNN control system using rotor flux estimator was developed to control PMSM drive system in order to drive electric scooter. The rotor flux estimator consists of the estimation algorithm of rotor flux position and speed based on the back electromagnetic force (EMF) in order to supply with HRFNN controller. The parameters of RFNN are trained according to different speeds in electric scooter. The electric scooter is operated to provide disturbance torque. From the experimental results, the control performance of the proposed HRFNN controller using rotor flux estimator is more suitable than PI controller for PMSM drive in electric scooter.

\section{Acknowledgment}

The author would like to acknowledge the financial support of the National Science Council in Taiwan, through its Grant NSC 99-2221-E-239-040-MY3.

\section{References}

[1] D. W. Novotny and T. A. Lipo, Vector Control and Dynamics of AC Drives, Oxford University Press, New York, NY, USA, 1996.

[2] W. Leonhard, Control of Electrical Drives, Springer, Berlin, Germany, 1996.

[3] F. J. Lin, "Real-time ip position controller design with torque feedforward control for pm synchronous motor," IEEE Transactions on Industrial Electronics, vol. 44, no. 3, pp. 398407, 1997.

[4] C. T. Lin and C. S. G. Lee, "Neural-network-based fuzzy logic control and decision system," IEEE Transactions on Computers, vol. 40, no. 12, pp. 1320-1336, 1991.

[5] Y. C. Chen and C. C. Teng, "A model reference control structure using a fuzzy neural network," Fuzzy Sets and Systems, vol. 73, no. 3, pp. 291-312, 1995.

[6] J. Zhang and A. J. Morris, "Fuzzy neural networks for nonlinear systems modelling," IEE Proceedings: Control Theory and Applications, vol. 142, no. 6, pp. 551-561, 1995.

[7] J. S. R. Jang and C. T. Sun, "Neuro-fuzzy modeling and control," Proceedings of the IEEE, vol. 83, no. 3, pp. 378-406, 1995.

[8] Y. G. Leu, T. T. Lee, and W. Y. Wang, "On-line tuning of fuzzyneural network for adaptive control of nonlinear dynamical systems," IEEE Transactions on Systems, Man, and Cybernetics B, vol. 27, no. 6, pp. 1034-1043, 1997.

[9] F. J. Lin, W. J. Hwang, and R. J. Wai, "A supervisory fuzzy neural network control system for tracking periodic inputs," 
IEEE Transactions on Fuzzy Systems, vol. 7, no. 1, pp. 41-52, 1999.

[10] Y. S. Kung, "Design and implementation of a high-performance PMLSM drives using DSP chip," IEEE Transactions on Industrial Electronics, vol. 55, no. 3, pp. 1341-1351, 2008.

[11] E. Kim and S. Lee, "Output feedback tracking control of MIMO systems using a fuzzy disturbance observer and its application to the speed control of a PM synchronous motor," IEEE Transactions on Fuzzy Systems, vol. 13, no. 6, pp. 725-741, 2005.

[12] F. J. Lin, P. H. Shen, and R. F. Fung, "RFNN control for PMLSM drive via backstepping technique," IEEE Transactions on Aerospace and Electronic Systems, vol. 41, no. 2, pp. 620-644, 2005.

[13] F. J. Lin and P. H. Shen, "Adaptive fuzzy-neural-network control for a DSP-based permanent magnet linear synchronous motor servo drive," IEEE Transactions on Fuzzy Systems, vol. 14, no. 4, pp. 481-495, 2006.

[14] C. F. Juang and J. S. Chen, "A recurrent fuzzy-network-based inverse modeling method for a temperature system control," IEEE Transactions on Systems, Man and Cybernetics C, vol. 37, no. 3, pp. 410-417, 2007.

[15] S. Cao, B. Wang, J. Zheng, W. Huang, L. Weng, and W. Yan, "Hysteresis compensation for giant magnetostrictive actuators using dynamic recurrent neural network," IEEE Transactions on Magnetics, vol. 42, no. 4, pp. 1143-1146, 2006.

[16] F. J. Lin, P. H. Shen, S. L. Yang, and P. H. Chou, "Recurrent radial basis function network-based fuzzy neural network control for permanent-magnet linear synchronous motor servo drive," IEEE Transactions on Magnetics, vol. 42, no. 11, pp. 3694-3705, 2006.

[17] J. S. Wang and C. S. G. Lee, "Self-adaptive recurrent neurofuzzy control of an autonomous underwater vehicle," IEEE Transactions on Robotics and Automation, vol. 19, no. 2, pp. 283-295, 2003.

[18] F. J. Lin, S. Y. Chen, L. T. Teng, and H. Chu, "Recurrent functional-link-based fuzzy neural network controller with improved particle swarm optimization for a linear synchronous motor drive," IEEE Transactions on Magnetics, vol. 45, no. 8, pp. 3151-3165, 2009.

[19] W. T. Su and C. M. Liaw, "Adaptive positioning control for a LPMSM drive based on adapted inverse model and robust disturbance observer," IEEE Transactions on Power Electronics, vol. 21, no. 2, pp. 505-517, 2006.

[20] K. K. Tan, T. H. Lee, H. F. Dou, S. J. Chin, and S. Zhao, "Precision motion control with disturbance observer for pulsewidth-modulated-driven permanent-magnet linear motors," IEEE Transactions on Magnetics, vol. 39, no. 3, pp. 1813-1818, 2003.

[21] H. C. Nho and P. Meckl, "Intelligent feedforward control and payload estimation for a two-link robotic manipulator," IEEE/ASME Transactions on Mechatronics, vol. 8, no. 2, pp. 277-283, 2003.

[22] C. H. Lee and C. C. Teng, "Identification and control of dynamic systems using recurrent fuzzy neural networks," IEEE Transactions on Fuzzy Systems, vol. 8, no. 4, pp. 349-366, 2000.

[23] J. J. E. Slotine and W. Li, Applied Nonlinear Control, PrenticeHall, Englewood Cliffs, NJ, USA, 1991.

[24] K. J. Astrom and B. Wittenmark, Adaptive Control, AddisonWesley, New York, NY, USA, 1995. 

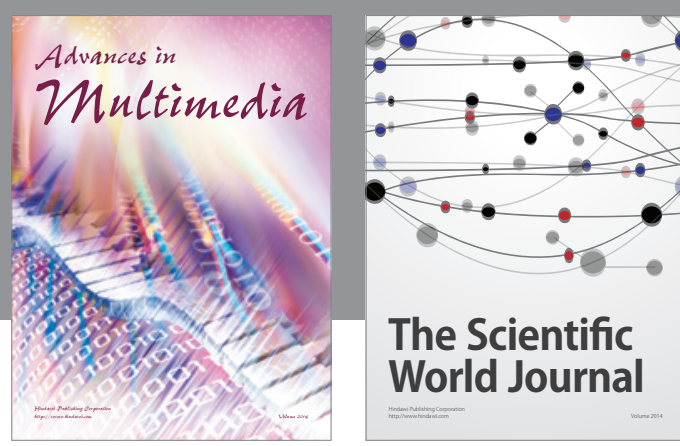

The Scientific World Journal
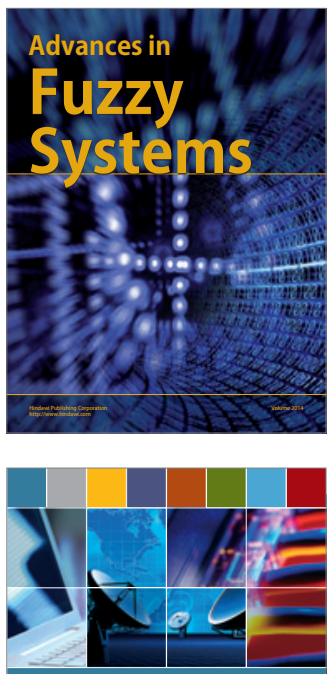

Computer Networks and Communications
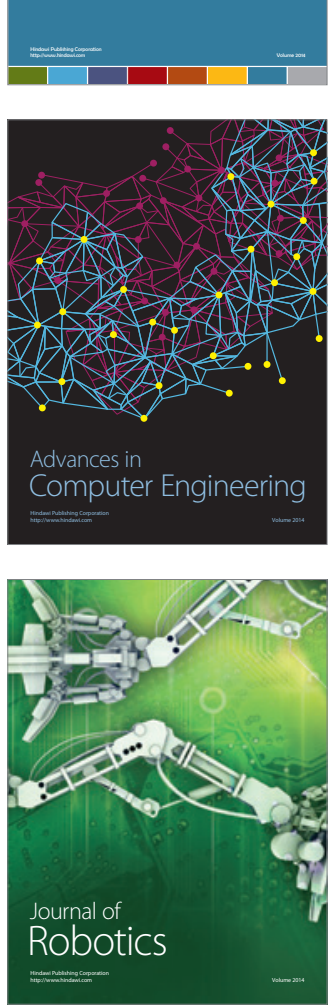
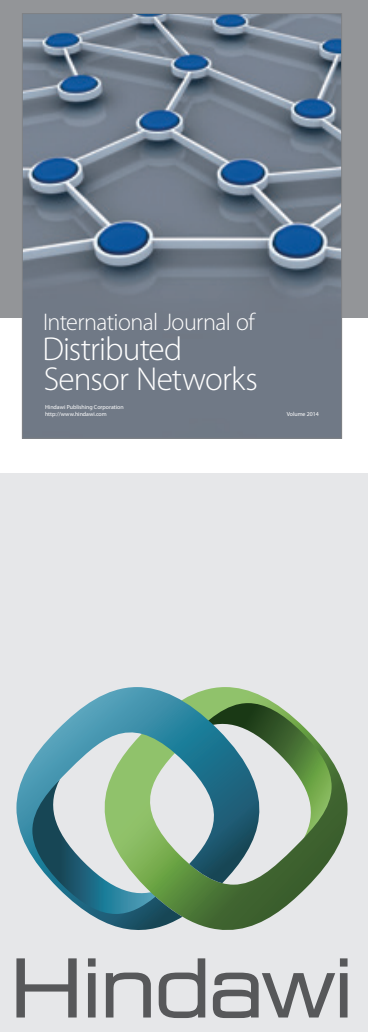

Submit your manuscripts at

http://www.hindawi.com
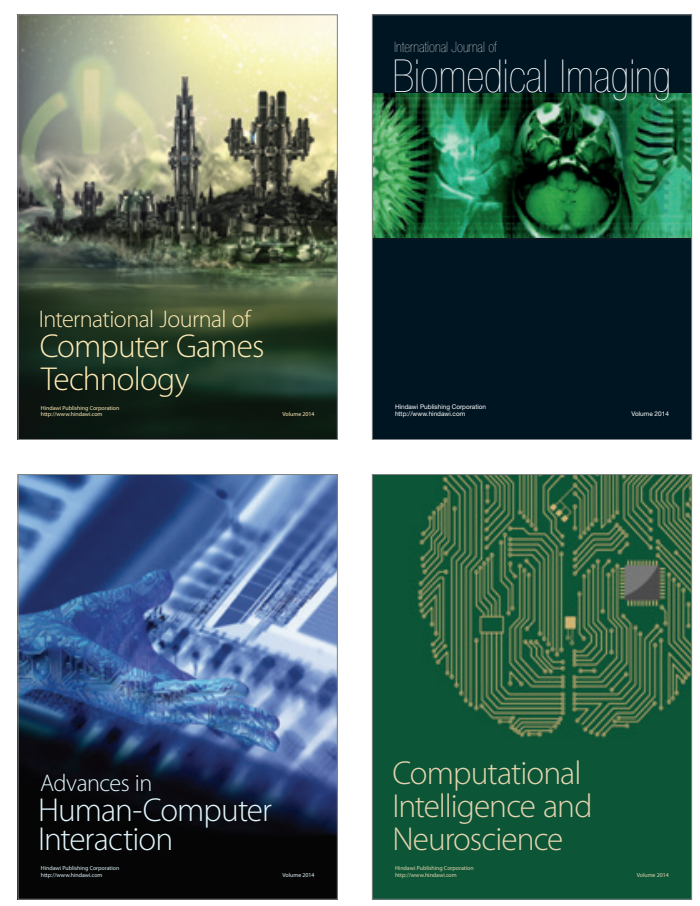
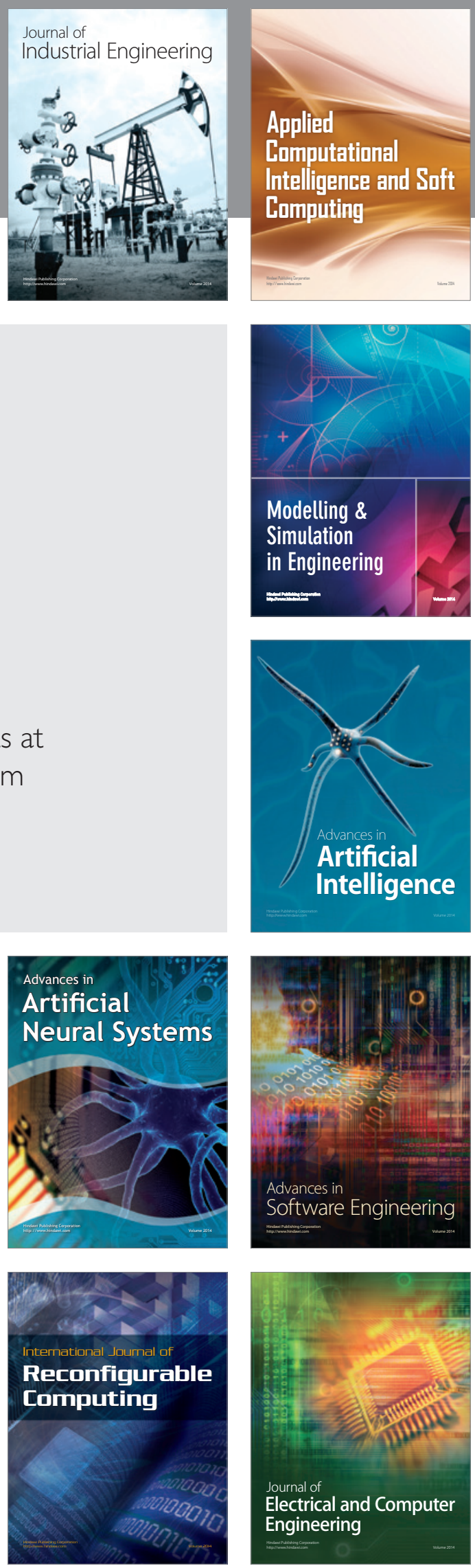